\title{
Risk factors for development of endocarditis and reintervention in patients undergoing right ventricle to pulmonary artery valved conduit placement
}

\author{
Carlos M. Mery, MD, MPH, ${ }^{a}$ Francisco A. Guzmán-Pruneda, MD, ${ }^{a}$ Luis E. De León, MD,,${ }^{\text {a,b }}$ \\ Wei Zhang, PhD, ${ }^{\mathrm{c}}$ Matthew D. Terwelp, BS, ${ }^{\mathrm{d}}$ Claire E. Bocchini, MD, ${ }^{\mathrm{e}}$ Iki Adachi, MD, ${ }^{\mathrm{a}}$ \\ Jeffrey S. Heinle, MD, ${ }^{a}$ E. Dean McKenzie, MD, ${ }^{a}$ and Charles D. Fraser, Jr, MD
}

\begin{abstract}
Objective: To determine the incidence and risk factors for endocarditis and reintervention in patients undergoing placement of right ventricle-to-pulmonary artery valve conduits.
\end{abstract}

Methods: All right ventricle-to-pulmonary artery valved conduits placed between 1995 and 2014 were included. Freedom from endocarditis, reintervention, and replacement were analyzed using the Kaplan-Meier method and parametric survival regression models.

Results: A total of 586 patients underwent placement of a total of 792 valved conduits, including $289(36 \%)$ pulmonary homografts, 121 (15\%) aortic homografts, $245(31 \%)$ bovine jugular grafts, and $137(17 \%)$ porcine heterografts. There were $474(60 \%)$ primary placements and $318(40 \%)$ replacements. The median duration of conduit follow-up was 7 years; 23 conduits developed endocarditis at a median of 5 years after surgery. The use of bovine jugular grafts was the sole significant risk factor associated with endocarditis (hazard ratio, 9.05; 95\% confidence interval, 2.6-31.8 compared with homografts). The hazard was greater for bovine jugular grafts compared with the other conduit types and increased with time; however, bovine jugular grafts were associated with a lower risk for reintervention $(P<.0001)$ and replacement $(P=.0002)$. Factors associated with greater risk of both reintervention and replacement were younger age and smaller conduit size. In addition, a diagnosis of truncus arteriosus was associated with a greater risk for replacement $(P=.03)$.

Conclusions: Bovine jugular grafts are associated with a significantly greater risk of late endocarditis but with lower reintervention rates compared with other valved conduits. The risk of endocarditis and durability must be balanced during conduit selection. Antibiotic prophylaxis and a high index of suspicion for endocarditis are warranted in patients with bovine jugular grafts. (J Thorac Cardiovasc Surg 2016;151:432-41)

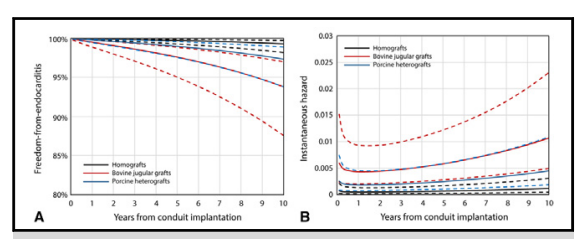

Bovine jugular grafts are associated with a greater risk of late endocarditis.

\section{Central Message}

Bovine jugular grafts are associated with a 9fold greater risk of late endocarditis and lower reintervention rates compared with other RVPA conduits.

\section{Perspective}

There is no perfect RV-PA conduit. Bovine jugular grafts are associated with both a greater risk of late endocarditis and lower reintervention/replacement rates compared with other conduits. One must balance the risks of endocarditis and conduit durability when selecting the best conduit. Antibiotic prophylaxis and a high index of suspicion for endocarditis are warranted in patients with bovine jugular grafts.

See Editorial Commentary page 442.

\footnotetext{
From the a'Division of Congenital Heart Surgery, Texas Children's Hospital, Michael E. DeBakey Department of Surgery, Baylor College of Medicine, Houston, Tex; ${ }^{\mathrm{b}}$ Tecnológico de Monterrey Medical School, Monterrey, Mexico; ' Outcomes and Impact Service, Texas Children's Hospital, Houston, Tex; ${ }^{\mathrm{d} U n i v e r s i t y ~ o f ~ T e x a s ~}$ Medical School, Houston, Tex; and ${ }^{\mathrm{e}}$ Division of Infectious Diseases, Texas Children's Hospital, Baylor College of Medicine, Houston, Tex.

Read at the 95th Annual Meeting of The American Association for Thoracic Surgery, Seattle, Washington, April 25-29, 2015.

Received for publication May 1, 2015; revisions received Sept 29, 2015; accepted for publication Oct 11, 2015; available ahead of print Dec 6, 2015.

Address for reprints: Carlos M. Mery, MD, MPH, Congenital Heart Surgery, Texas Children's Hospital, 6621 Fannin St MC19345H, Houston, TX 77030 (E-mail: cmmery@texaschildrens.org).

$0022-5223 / \$ 36.00$

Copyright (c) 2016 by The American Association for Thoracic Surgery

http://dx.doi.org/10.1016/j.jtcvs.2015.10.069
}

Ð Supplemental material is available online.

Various valved conduits are available for the restoration of right ventricle-to-pulmonary artery (RV-PA) continuity. Each offers inherent advantages and limitations, without a clear indication as to which conduit provides the best performance. ${ }^{1,2}$ There are contradicting reports in the literature regarding the durability of the different conduits, and as such, the ideal conduit remains a subject 


\section{Abbreviations and Acronyms \\ $\mathrm{CI}=$ confidence interval \\ $\mathrm{CRP}=\mathrm{C}$-reactive protein \\ ESR = erythrocyte sedimentation rate \\ HR = hazard ratio \\ MSSA = methicillin-sensitive Staphylococcus aureus \\ $\mathrm{PA} / \mathrm{VSD}=$ pulmonary atresia with ventricular septal defect \\ SE $\quad=$ standard error}

of debate. Anecdotally, we have encountered a concerning incidence of late endocarditis in patients with bovine jugular vein graft RV-PA conduits. This concern has been raised by recent series as well. ${ }^{3-6}$ If this concern is indeed warranted, then the incidence of endocarditis and longterm durability for each conduit type must be taken into account when determining the best RV-PA conduit to implant on a particular patient.

The goal of this study was to determine the incidence of late endocarditis and risk factors for conduit failure in patients undergoing placement of bovine jugular, pulmonary, and aortic homografts and porcine heterograft valved conduits in the RV-PA position.

\section{METHODS}

The study cohort included all patients who underwent surgical placement of an RV-PA valved conduit at Texas Children's Hospital between 1995 and 2014. Valved conduits arising from a morphological left ventricle in the setting of congenitally corrected transposition of the great arteries were included in the study. This study was approved by Baylor College of Medicine's Institutional Review Board, and informed consent was waived.

All demographic and clinical data were collected by retrospective review of all medical records, operative reports, procedure notes, discharge notes, and clinic notes. Follow-up was obtained through a combination of clinic notes and telephone interviews of patients, families, and referring physicians. Perioperative mortality was defined as death before hospital discharge or within 30 days after surgery.

The type of valved conduit was classified as pulmonary homograft, aortic homograft, bovine jugular graft (Contegra pulmonary valved conduit; Medtronic, Minneapolis, Minn), and porcine heterograft (Hancock bioprosthetic valved conduit; Medtronic). All homografts were cryopreserved and provided by LifeNet, CryoLife, or RTI/Alabama Tissue Bank. Two patients who underwent placement of a porcine aortic root bioprosthesis (Freestyle tissue valve; Medtronic) were not included in the study. For some analyses, aortic and pulmonary homografts were combined.

The cohort was divided into the following diagnostic groups: pulmonary atresia with ventricular septal defect with or without major aortopulmonary collaterals, truncus arteriosus, Ross operation, and other (ie, history of nonconduit tetralogy of Fallot repair, absent pulmonary valve syndrome, pulmonary atresia with intact ventricular septum, double-outlet right ventricle, transposition of the great arteries with pulmonary stenosis or atresia). Conduit $z$-score was calculated based on the listed implant diameter and published formulas for the main pulmonary artery based on body surface area. ${ }^{7}$ Significant conduit stenosis was defined as a peak gradient
$>3 \mathrm{~m} / \mathrm{s}$ across the conduit. Significant conduit regurgitation was defined as echocardiographic evidence of moderate or severe regurgitation.

Endocarditis was defined as possible or definitive based on modified Duke criteria. ${ }^{8}$ Reintervention was defined as the need for catheter-based intervention (balloon angioplasty or stent placement), placement of a transcatheter pulmonary valve (Melody transcatheter pulmonary valve; Medtronic), or surgical replacement. For freedom-from-reintervention analyses, only the first reintervention was analyzed. Isolated interventions to the branch pulmonary arteries were not considered reinterventions. Replacement was defined as the need for either transcatheter pulmonary valve placement or surgical replacement.

\section{Data Analysis}

All analyses were performed for each conduit rather than for each patient. Descriptive analyses were performed for the entire cohort and for each group. Data are described as percentages and medians with ranges, as appropriate. Univariate analyses were performed using $\chi^{2}$ and KruskalWallis tests, as appropriate. Univariate analyses for freedom from endocarditis, freedom from first reintervention, and freedom from replacement were performed using the Kaplan-Meier method and log-rank tests. Continuous variables were divided in quartiles for univariate analysis and variable selection. For analysis of freedom from endocarditis, noninfected conduits were censored at the time of surgical replacement or placement of a transcatheter pulmonary valve. For patients who died, conduits were censored at the time of death.

For multivariate analyses, parametric survival analysis models were created using decomposition of time-varying hazards to identify risk factors for endocarditis, first reintervention, and replacement. ${ }^{9}$ Because analyses were performed by conduit rather than by patient, events were modeled as repeated occurrences by including a variable for conduit placement versus replacement in the models. This modulated renewal process methodology allowed censoring of conduits at the time of replacement while still accounting for previous conduit history. In addition, to test the renewal assumption, additional models were created for patients that had all conduits placed at our institution including, as a variable, the time spent with a previous conduit before the current placement. The time spent with a previous conduit was not significant in any of the models. Final models were created including clinically and statistically significant terms. Interaction terms between different variables were tested in the models but found to be nonsignificant. Results are reported as coefficients with standard errors and corresponding hazard ratios (HRs) with 95\% confidence intervals (CIs). A $P$ value $<.05$ was considered statistically significant.

All analyses were carried out using SAS for Windows 9.4 (SAS Institute, Cary, NC) and the Hazard Package provided by The Cleveland Clinic Foundation. ${ }^{9}$

\section{RESULTS}

A total of 586 unique patients underwent placement of 792 valved conduits (Table 1). The median age at conduit placement was 4 years (range, 3 days to 47 years). Among the 586 patients, $196(25 \%)$ had an identified genetic syndrome, with DiGeorge syndrome the most common $(\mathrm{n}=91 ; 47 \%)$.

Valved conduits included pulmonary homografts $(\mathrm{n}=289 ; 36 \%)$, aortic homografts $(\mathrm{n}=121 ; 15 \%)$, bovine jugular grafts $(\mathrm{n}=245 ; 31 \%)$, and porcine heterografts $(\mathrm{n}=137 ; 17 \%)$. A total of $474(60 \%)$ primary conduit placements and $318(40 \%)$ replacements were performed at our institution. Of these 318 replacements, $250(79 \%)$ had 1 previous RV-PA conduit, $61(19 \%)$ had 2 conduits, 
TABLE 1. Characteristics of patients undergoing conduit implantation

\begin{tabular}{|c|c|c|c|c|c|}
\hline Variable & $\begin{array}{c}\text { Overall } \\
(n=792)\end{array}$ & $\begin{array}{c}\text { Homograft } \\
(n=410)\end{array}$ & $\begin{array}{c}\text { Bovine jugular graft } \\
(\mathrm{n}=\mathbf{2 4 5})\end{array}$ & $\begin{array}{l}\text { Porcine heterograft } \\
\quad(\mathbf{n}=137)\end{array}$ & $P$ value \\
\hline Female sex, n (\%) & $338(57)$ & $172(58)$ & $136(56)$ & $81(59)$ & .93 \\
\hline Weight, kg, median (range) & $15(1.7-136)$ & $12(1.7-136)$ & $12(2-77)$ & $33(7-109)$ & $<.0001$ \\
\hline Age, y, median (range) & 4 y $(3 \mathrm{~d}-47 \mathrm{y})$ & 3 y $(3 \mathrm{~d}-45 \mathrm{y})$ & $3 \mathrm{y}(15 \mathrm{~d}-45 \mathrm{y})$ & 12 y (1 y-47 y) & $<.0001$ \\
\hline Age groups, n (\%) & & & & & $<.0001$ \\
\hline Neonates and infants & $214(27)$ & $150(36)$ & $64(26)$ & $0(0)$ & \\
\hline $1-4$ y & $220(28)$ & 99 (24) & $99(40)$ & $22(16)$ & \\
\hline $5-9$ y & $121(15)$ & $50(12)$ & $35(14)$ & $36(26)$ & \\
\hline $10-18$ y & $172(22)$ & $78(19)$ & $41(17)$ & $53(38)$ & \\
\hline$>18 \mathrm{y}$ & $65(8)$ & $33(8)$ & $6(2)$ & $26(19)$ & \\
\hline Diagnosis & & & & & $<.0001$ \\
\hline PA/VSD & $252(32)$ & $106(26)$ & $90(37)$ & $52(38)$ & \\
\hline Truncus & $181(23)$ & $92(22)$ & $64(26)$ & $25(18)$ & \\
\hline Ross operation & $116(15)$ & $97(24)$ & $15(6)$ & $4(3)$ & \\
\hline Other* & $243(31)$ & $115(28)$ & $76(31)$ & $52(38)$ & \\
\hline \multicolumn{6}{|l|}{ Conduit sequence } \\
\hline Primary placement & $474(60)$ & $321(78)$ & $128(52)$ & $25(18)$ & \\
\hline Replacement & $318(40)$ & $89(22)$ & $117(48)$ & $112(82)$ & \\
\hline Conduit size, mm, median (range) & $18(8-30)$ & $17(8-30)$ & $16(12-22)$ & $18(8-30)$ & $<.0001$ \\
\hline
\end{tabular}

PA/VSD, Pulmonary atresia with ventricular septal defect. *Includes history of nonconduit tetralogy of Fallot repair, transposition of the great arteries with pulmonary stenosis or pulmonary atresia, absent pulmonary valve syndrome, pulmonary atresia with intact ventricular septum, and double-outlet right ventricle.

and $7(2 \%)$ had 3 or more conduits. The majority of homografts $(\mathrm{n}=321 ; 78 \%)$ and bovine jugular grafts $(\mathrm{n}=128 ; 52 \%)$ were used as primary conduits, whereas the majority of porcine heterografts $(\mathrm{n}=112 ; 82 \%)$ were used as replacement conduits.

The median duration of conduit follow-up was 7 years (range, 6 days to 20 years). During follow-up, there were 37 mortalities, including 18 perioperative deaths.

\section{Endocarditis}

During the follow-up period, 23 conduits developed endocarditis, at a median of 5 years (range, 19 days to 11 years) after surgery. Clinical characteristics by conduit type are presented in Table 2.

Five-, 10-, and 15-year freedom-from-endocarditis rates were $98 \%, 93 \%$, and $92 \%$, respectively. The most common infectious agents were viridans streptococci $(\mathrm{n}=10 ; 43 \%)$ and methicillin-sensitive Staphylococcus aureus $(\mathrm{n}=4$; $17 \%)$. Sixteen conduits $(70 \%)$ have been replaced surgically for endocarditis, whereas $7(30 \%)$ have been managed medically. Two patients who were initially managed medically for endocarditis (1 with Streptococcus viridans and the other with Staphylococcus epidermidis) required replacement of the conduit for recurrent symptoms and positive blood cultures at 3 months and 10 months after initial presentation, respectively. None of the patients with endocarditis died of related causes. Of the 16 infected conduits surgically replaced, $13(81 \%)$ were replaced with homografts and $3(19 \%)$ were replaced with bovine jugular grafts. None of these conduits developed recurrent endocarditis at a median of 2 years (range, 2 months to 6 years) after replacement.
On univariate analysis, type of conduit was significantly associated with the risk of endocarditis $(P=.0018)$. In particular, bovine jugular vein grafts were associated with an increased risk of late endocarditis, especially after 7 years (Figure 1). The actuarial 10-year freedom from endocarditis was $83 \%$ for bovine jugular grafts, compared with $100 \%$ for aortic homografts, $98 \%$ for pulmonary homografts, and $95 \%$ for porcine heterografts. No other factor, including age, gender, diagnosis, conduit size, conduit sequence (initial placement vs replacement), or history of endocarditis, was significantly associated with endocarditis on univariate analyses.

On multivariate analysis, conduit type was the sole variable significantly associated with the development of endocarditis (Table 3). Bovine jugular grafts were associated, on average, with a 9-fold greater risk for endocarditis compared with homografts $(P=.0006)$. Figure 2 depicts risk-adjusted parametric estimates of freedom from endocarditis for the different conduit types and the instantaneous hazard for development of endocarditis for each particular conduit type by time elapsed from conduit placement. The HR for bovine jugular grafts was higher than that for the other conduit types and increased with time.

\section{Reintervention and Replacement}

A total of 290 (37\%) conduits required 1 or more reinterventions, for a total of 391 interventions. Interventions included $87(22 \%)$ balloon dilations, $54(14 \%)$ stent placements, $33(8 \%)$ transcatheter pulmonary valve placements, and $217(55 \%)$ surgical replacements. The most common first reintervention was surgical replacement, 
TABLE 2. Characteristics and clinical presentation of patients diagnosed with infective endocarditis

\begin{tabular}{|c|c|c|c|c|}
\hline Variable & $\begin{array}{c}\text { Overall } \\
(\mathrm{n} / \mathrm{N}=\mathbf{2 3 / 7 9 2})\end{array}$ & $\begin{array}{c}\text { Homograft } \\
(n / N=4 / 410)\end{array}$ & $\begin{array}{l}\text { Bovine jugular graft } \\
\quad(n / N=14 / 245)\end{array}$ & $\begin{array}{l}\text { Porcine heterograft } \\
\quad(\mathrm{n} / \mathbf{N}=\mathbf{5 / 1 3 7})\end{array}$ \\
\hline Time from conduit surgery to diagnosis, median (range) & 5 y $(19 \mathrm{~d}-11 \mathrm{y})$ & 5 y $(19 \mathrm{~d}-11 \mathrm{y})$ & 7 y (34 d-10 y) & $2 y(1 y-5 y)$ \\
\hline Age at time of diagnosis, median (range) & 12 y $(28 \mathrm{~d}-23 \mathrm{y})$ & 15 y $(28 \mathrm{~d}-23 \mathrm{y})$ & 13 y $(1 \mathrm{y}-21 \mathrm{y})$ & $9 y(6 y-13 y)$ \\
\hline Female sex, n $(\%)$ & $9(39)$ & $0(0)$ & $5(36)$ & $4(80)$ \\
\hline Surgical replacement, $\mathrm{n}(\%)$ & $16(70)$ & $2(50)$ & $11(79)$ & $3(60)$ \\
\hline Duration of symptoms at presentation, median (range) & $14 \mathrm{~d}(1 \mathrm{~d}-180 \mathrm{~d})$ & $7 \mathrm{~d}(1 \mathrm{~d}-13 \mathrm{~d})$ & $21 \mathrm{~d}(3 \mathrm{~d}-180 \mathrm{~d})$ & $7 d(2 d-21 d)$ \\
\hline \multicolumn{5}{|l|}{ Diagnosis of endocarditis, $\mathrm{n}(\%)^{*}$} \\
\hline Definite & $18(78)$ & $3(75)$ & $12(86)$ & $3(60)$ \\
\hline Possible & $5(22)$ & $1(25)$ & $2(14)$ & $2(40)$ \\
\hline Pathological diagnosis, $\mathrm{n}(\%) \dagger$ & $10(43)$ & $0(0)$ & $8(57)$ & $2(40)$ \\
\hline \multicolumn{5}{|l|}{ Major clinical criteria, $\mathrm{n}(\%) *$} \\
\hline Echocardiogram findings & $18(78)$ & $3(75)$ & $12(86)$ & $3(60)$ \\
\hline Blood culture & $14(61)$ & $1(25)$ & $9(64)$ & $4(80)$ \\
\hline \multicolumn{5}{|l|}{ Minor clinical criteria, $\mathrm{n}(\%)^{*}$} \\
\hline Predisposing cardiac lesion & $23(100)$ & $4(100)$ & $14(100)$ & $5(100)$ \\
\hline Fever & $22(96)$ & $4(100)$ & $14(100)$ & $4(80)$ \\
\hline Vascular phenomena & $4(17)$ & $1(25)$ & $2(14)$ & $1(20)$ \\
\hline Immunologic phenomena & $3(13)$ & $0(0)$ & $1(7)$ & $2(40)$ \\
\hline Microbiological evidence (not included above) & $5(22)$ & $2(50)$ & $3(21)$ & $0(0)$ \\
\hline \multicolumn{5}{|l|}{ Microbiology, n (\%) } \\
\hline Viridans streptococci & $10(43)$ & $2(50)$ & $7(50)$ & $1(20)$ \\
\hline Staphylococcus aureus (MSSA) & $4(17)$ & $0(0)$ & $3(21)$ & $1(20)$ \\
\hline Other $\ddagger$ & $6(26)$ & $2(50)$ & $2(14)$ & $2(40)$ \\
\hline Negative cultures & $3(13)$ & $0(0)$ & $2(14)$ & $1(20)$ \\
\hline \multicolumn{5}{|l|}{ Laboratory findings, median (range) } \\
\hline White blood cell count, $10^{3} / \mu \mathrm{L}$ & $9.0(3.3-24)$ & $8.5(4.4-24)$ & $9.0(3.3-17.2)$ & $7.8(6.6-19)$ \\
\hline Hemoglobin, g/dL & $11.4(4.9-14.9)$ & $12.2(11.5-13.5)$ & $10.0(4.9-14.9)$ & $12.9(11.2-14)$ \\
\hline Platelet count, $10^{3} / \mu \mathrm{L}$ & $174(57-473)$ & $165(112-334)$ & $226(81-473)$ & $143(57-149)$ \\
\hline Erythrocyte sedimentation rate, $\mathrm{mm} / \mathrm{h}$ & $37(7-136)$ & $29(7-40)$ & $47(21-136)$ & $15(12-18)$ \\
\hline C-reactive protein, $\mathrm{mg} / \mathrm{dL}$ & $6.5(0.6-31.1)$ & $5.3(0.6-29.9)$ & $6.5(0.8-31.3)$ & $13.7(3.4-24)$ \\
\hline
\end{tabular}

MSSA, Methicillin-sensitive $S$ aureus. *Based on modified Duke criteria [8]. †Positive culture from vegetation or histopathology consistent with infective endocarditis. $\ddagger$ Two cases of Staphylococcus epidermidis and 1 case each of Granulicatella adiacens, Streptococcus pneumoniae, Cardiobacterium hominis, and Enterococcus faecalis.

performed in 151 patients $(52 \%)$, followed by balloon dilation in $75(26 \%)$, stent placement in $42(14 \%)$, and transcatheter pulmonary valve placement in $22(8 \%)$. Of the 174 conduits that underwent a catheter-based intervention as initial therapy, $101(86 \%)$ conduits had stenosis and $65(55 \%)$ had regurgitation. In contrast, of the 151 conduits that had surgical replacement as the initial reintervention strategy, $102(68 \%)$ had insufficiency, $98(65 \%)$ had stenosis, and $20(13 \%)$ had a pseudoaneurysm.

The status of the conduit at the time of first reintervention varied by conduit type (Table E1). The majority of homografts that required reintervention $(\mathrm{n}=130 ; 70 \%)$ had moderate to severe insufficiency, compared with 40 bovine jugular grafts $(60 \%)$ and 8 porcine heterografts $(22 \%)(P<.0001)$. The overall presence of significant stenosis $(66 \%-78 \%)$ was similar among the different conduits, but stenosis was most commonly seen at the distal anastomosis in bovine jugular grafts and at the proximal anastomosis or within the conduit in porcine heterografts.
Overall freedom from first reintervention at 5, 10, and 15 years was $73 \%, 45 \%$, and $26 \%$, respectively (Figure 3). On univariate analysis, variables significantly associated with increased reintervention rates included younger age, diagnosis, conduit type, smaller conduit size, and lower conduit $z$-score (all comparisons $P<.0001)$. On multivariate analysis, younger age and smaller conduit size were associated with a lower risk for reintervention (Table 4). The risk-adjusted relationships between age or conduit size and first reintervention are shown in Figure E1. Replacements of previous conduits did not have a higher rate of reintervention than primary conduits (Table 4). There was a tendency for a diagnosis of truncus arteriosus to be associated with higher reintervention rates, but it did not reach statistical significance $(P=.0563)$. Bovine jugular grafts were associated with a significantly lower incidence of first reintervention compared with pulmonary homografts. There was no difference in reintervention rates among the other conduits. Figure E2 shows risk-adjusted estimates of 


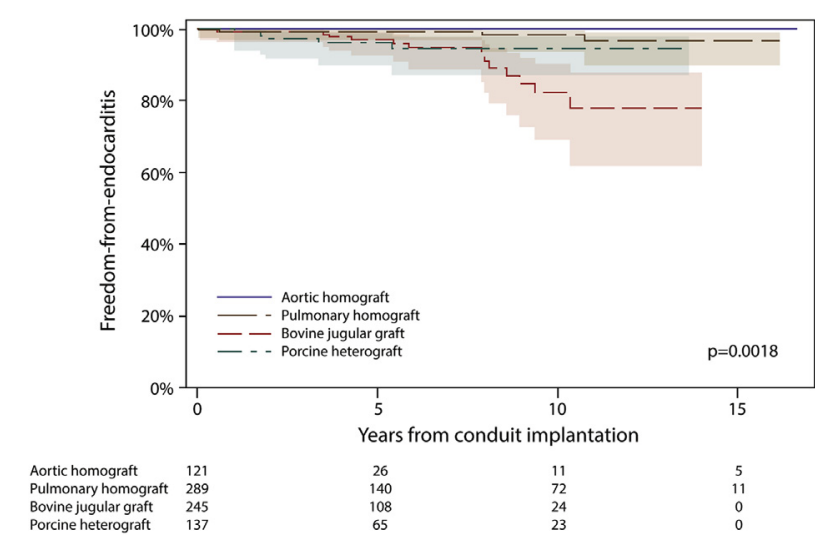

FIGURE 1. Kaplan-Meier curves depicting freedom from endocarditis by conduit type. Bovine jugular grafts had a significantly higher incidence of endocarditis than aortic homografts $(P=.0005)$, pulmonary homografts $(P=.0006)$, and porcine heterografts $(P=.035)$. No other comparisons were significantly different.

freedom from first reintervention for the different conduit types.

Overall freedom from surgical replacement or transcatheter pulmonary valve implantation at 5,10 , and 15 years was $79 \%, 52 \%$, and $32 \%$, respectively. On univariate analysis, variables associated with valve replacement included younger age, conduit type, diagnosis, smaller conduit size (all comparisons $P<.0001$ ), and lower conduit $z$-score $(P=.0009)$. After adjustment for covariates, younger age, a smaller conduit size, and a diagnosis of truncus arteriosus were associated with higher rates of conduit replacement (Table 4). Compared with pulmonary homografts, bovine jugular grafts were associated with a lower risk of replacement.

TABLE 3. Multivariate analysis for development of endocarditis

\begin{tabular}{|c|c|c|c|}
\hline Variable & Coefficient $\pm \mathrm{SE}$ & HR $(95 \%$ CI $)$ & $P$ value \\
\hline Age (y) & $-0.02 \pm 0.05$ & $0.98(0.88-1.1)$ & .784 \\
\hline Conduit size $(\mathrm{mm})$ & $0.11 \pm 0.1$ & $1.11(0.91-1.35)$ & .3242 \\
\hline \multicolumn{4}{|l|}{ Conduit type } \\
\hline Homograft & Reference & & \\
\hline Bovine jugular graft & $2.2 \pm 0.64$ & $9.05(2.57-31.83)$ & .0006 \\
\hline Porcine heterograft & $1.34 \pm 0.75$ & $3.82(0.87-16.71)$ & .0749 \\
\hline \multicolumn{4}{|l|}{ Conduit sequence } \\
\hline Primary placement & Reference & & \\
\hline Replacement & $0.09 \pm 0.52$ & $1.1(0.39-3.05)$ & .8593 \\
\hline \multicolumn{4}{|l|}{ Diagnosis } \\
\hline PA/VSD & Reference & & \\
\hline Truncus & $0.19 \pm 0.64$ & $1.21(0.35-4.19)$ & .7682 \\
\hline Ross operation & $0.58 \pm 0.79$ & $1.78(0.38-8.32)$ & .4621 \\
\hline Other* & $0.59 \pm 0.55$ & $1.81(0.62-5.29)$ & .2809 \\
\hline$z$-score & $0.07 \pm 0.29$ & $1.08(0.61-1.9)$ & .7992 \\
\hline
\end{tabular}

$S E$, Standard error; $H R$, hazard ratio; $C I$, confidence interval; $P A / V S D$, pulmonary atresia with ventricular septal defect. *Includes history of nonconduit tetralogy of Fallot repair, transposition of the great arteries with pulmonary stenosis or pulmonary atresia, absent pulmonary valve syndrome, pulmonary atresia with intact ventricular septum, and double-outlet right ventricle.

\section{DISCUSSION}

Multiple attempts to define the optimal RV-PA conduit for a particular patient have been elusive, with contradictory reports in the literature regarding the performance of different conduits. Furthermore, our own experience and some smaller series ${ }^{3-5,10}$ have raised concerns regarding the development of endocarditis in patients with a bovine jugular vein graft RV-PA conduit.

The goal of this large single-institution study including 792 conduits was to define the incidence of endocarditis and conduit failure for different types of RV-PA conduits, to help determine which conduit to use in a particular patient.

Some previous series have advocated the use of pulmonary homografts, reporting freedom-from-replacement rates as high as $99 \%$ at 10 years for patients age $>16$ years. $^{11}$ In contrast, other studies have reported homograft degeneration rates as high as $46 \%$ at 10 years in older patients and $65 \%$ at 5 years in younger ones. ${ }^{12}$ Porcine heterografts have also had mixed results. In a series of 401 patients, Lange and colleagues ${ }^{13}$ found that even though homografts and porcine heterografts behaved similarly for smaller conduits, among conduits $15 \mathrm{~mm}$ or larger, porcine heterografts had a higher risk for replacement. Similarly, Boethig and colleagues ${ }^{14}$ reported worse durability for porcine heterografts compared with homografts and bovine jugular grafts. In contrast, in a very large series, Dearani and colleagues ${ }^{2}$ showed overall better performance for porcine heterografts compared with homografts. A similar conclusion was reached by Ong and colleagues, ${ }^{15}$ who found that Dacron-based grafts were associated with longer longevity.

The use of bovine jugular vein conduits has increased over the last decade, owing to availability in a variety of sizes and ease of handling. Reported results have been mixed. In a multi-institutional propensity-matched study of 107 infants with truncus arteriosus, Hickey and colleagues ${ }^{16}$ found that bovine jugular grafts were associated with a lower risk for replacement than homografts, and that catheter intervention was more successful at slowing subsequent gradient progression in these conduits. Other series have found comparable outcomes between bovine jugular grafts and homografts ${ }^{14,17}$; other studies, however, have shown a high incidence of acquired distal conduit stenosis and early conduit insufficiency, especially among younger patients and in smaller conduits. ${ }^{10,18,19}$ Explanted conduits have demonstrated neointimal proliferation, thrombosis, calcification, and chronic inflammation, ${ }^{18}$ which may translate into an elevated risk of conduit degeneration. Consistent with these studies, Urso and colleagues $^{20}$ identified use of bovine jugular grafts as an independent risk factor for replacement with a 5-year freedom from replacement rate of $78 \%$ for bovine jugular grafts compared with $94 \%$ for homografts. 

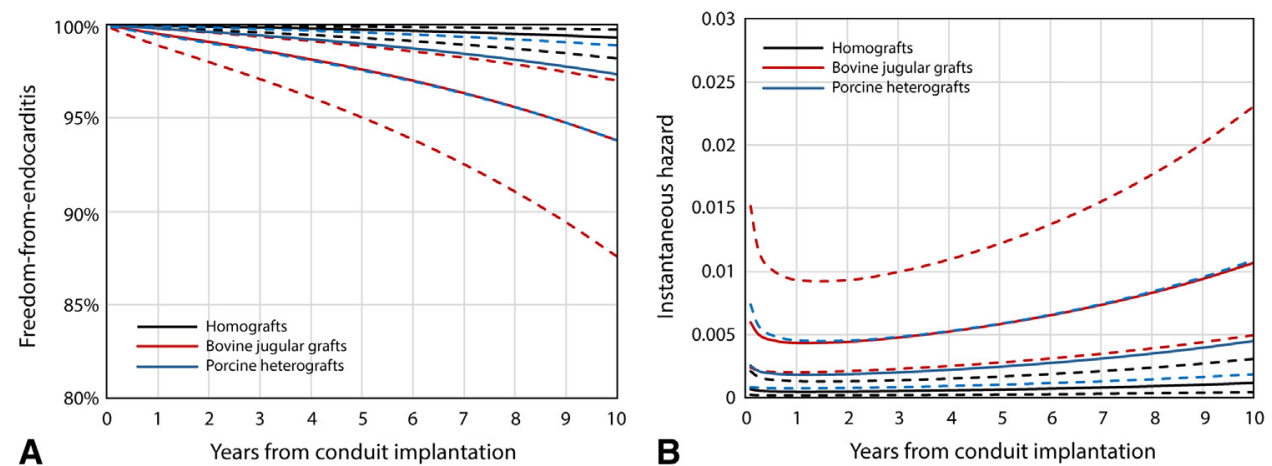

FIGURE 2. (A) Risk-adjusted parametric estimates for freedom from endocarditis by conduit type. The dashed lines correspond to confidence limits equivalent to 1 standard error $(68 \%)$. Bovine jugular grafts were associated with an increased risk of endocarditis compared with homografts $(P=.0005)$. (B) Risk-adjusted instantaneous hazard of developing endocarditis with time, stratified by conduit type.

In our study, reintervention and replacement rates were similar for pulmonary and aortic homografts. Our group favors the use of aortic homografts for patients at risk for pulmonary hypertension and those with truncus arteriosus, because the curvature of the graft seems to provide an ideal orientation. The effect of these alternative uses on durability is unclear. Bovine jugular grafts were associated with a lower rate of reintervention and replacement after adjusting for significant covariates. This effect seems robust, although it possibly could be related in part to unaccounted-for confounding factors that might have prompted the use of other conduits in patients at greater risk for reintervention.

An alarming finding of our study, however, is the high risk of late endocarditis in patients with a bovine jugular graft. Overall, $6 \%$ of bovine jugular vein conduits developed endocarditis during the study period. The use of bovine jugular grafts was associated a 9-times greater risk of endocarditis compared with homografts. Calculated estimates suggest that as many as $17 \%$ of patients with a

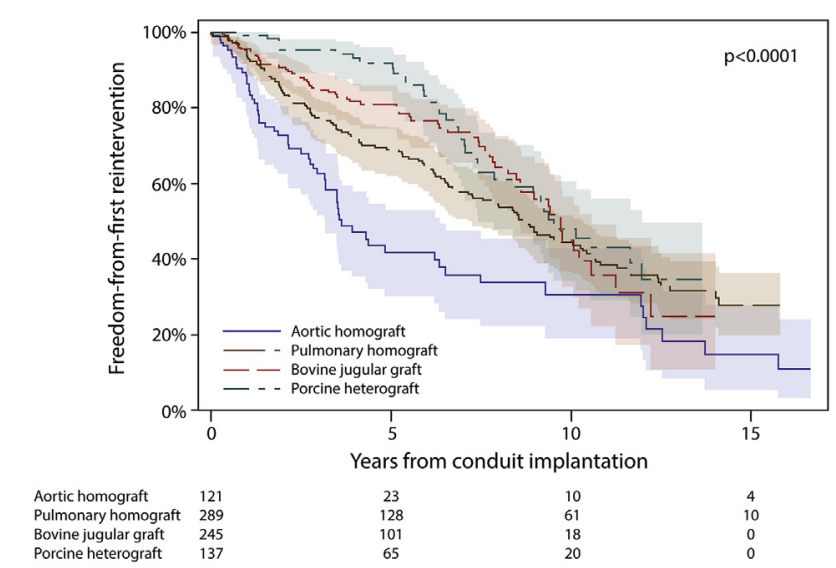

FIGURE 3. Freedom from first reintervention by conduit type. Shaded areas represent $95 \%$ CIs. The first reintervention rate was significantly higher for aortic homografts than for pulmonary homografts $(P=.029)$, bovine jugular grafts $(P<.0001)$, or porcine heterografts $(P<.0001)$. bovine jugular graft will develop endocarditis at 10 years after conduit placement. Interestingly, the risk of endocarditis seems to increase with time.

These results are consistent with previously reported series that have found an incidence of endocarditis among bovine jugular grafts of $7 \%$ to $11 \%$, compared with $<1 \%$ for homografts. ${ }^{3-5}$ The 5 -year freedom from endocarditis rate has been reported to be as low as $84 \%$ to $88 \%{ }^{5,6}$ In a recent study, Ugaki and colleagues ${ }^{3}$ analyzed 244 bovine jugular grafts and 135 homografts with a median follow-up of 3.4 years, and found that $9.4 \%$ of bovine jugular grafts became infected during the follow-up period, compared with $0.7 \%$ of the homografts. (A time-to-event analysis was not performed.) The majority of cases of endocarditis occurred more than 6 months after RV-PA conduit placement. Other smaller series also have shown a low incidence of endocarditis in the first year after implantation, with peaks between the second and third years and the fourth and fifth years. ${ }^{5}$

The mechanism behind the higher incidence of endocarditis in bovine jugular grafts is unclear, but may be associated with late tissue degeneration, turbulent flow, increased thrombogenicity, or a greater intrinsic susceptibility of these conduits to infection. Further basic science studies are needed to define the precise pathophysiological mechanism explaining this finding. It is at least plausible that the elevated risk of late endocarditis in these conduits may be related in part to the longer longevity of bovine jugular grafts compared with homografts, particularly if the homografts that were replaced earlier would have been at an increased risk for developing endocarditis had they remained in place. This hypothesis is unlikely to explain the significantly higher risk, however, especially given the higher instantaneous hazard of endocarditis for these conduits throughout the study period, and the still significant number of other conduits at risk late in the study.

Another interesting finding was the indolent clinical course of some patients with endocarditis who presented 
TABLE 4. Multivariate analysis for conduit reintervention and conduit replacement

\begin{tabular}{|c|c|c|c|c|c|c|}
\hline \multirow[b]{2}{*}{ Variable } & \multicolumn{3}{|c|}{ Reintervention } & \multicolumn{3}{|c|}{ Replacement } \\
\hline & Coefficient \pm SE & HR $(95 \%$ CI $)$ & $P$ value & Coefficient \pm SE & HR $(95 \%$ CI $)$ & $P$ value \\
\hline Age (y) & $-0.06 \pm 0.02$ & $0.95(0.9-0.99)$ & .0191 & $-0.07 \pm 0.03$ & $0.94(0.89-0.99)$ & .0133 \\
\hline Conduit size (mm) & $-0.11 \pm 0.03$ & $0.9(0.84-0.95)$ & .0004 & $-0.08 \pm 0.03$ & $0.92(0.87-0.99)$ & .0195 \\
\hline \multicolumn{7}{|l|}{ Conduit type } \\
\hline Pulmonary homograft & Reference & & & Reference & & \\
\hline Aortic homograft & $0.003 \pm 0.07$ & $1(0.88-1.14)$ & .9588 & $-0.09 \pm 0.19$ & $0.91(0.63-1.33)$ & .6251 \\
\hline Bovine jugular graft & $-0.62 \pm 0.15$ & $0.54(0.4-0.73)$ & $<.0001$ & $-0.67 \pm 0.18$ & $0.51(0.36-0.73)$ & .0002 \\
\hline Porcine heterograft & $-0.1 \pm 0.22$ & $0.9(0.59-1.39)$ & .6414 & $-0.07 \pm 0.24$ & $0.94(0.59-1.49)$ & .7805 \\
\hline \multicolumn{7}{|l|}{ Conduit sequence } \\
\hline Primary placement & Reference & & & Reference & & \\
\hline Replacements & $0.08 \pm 0.18$ & $1.09(0.77-1.54)$ & .6434 & $-0.15 \pm 0.19$ & $0.86(0.59-1.25)$ & .4309 \\
\hline \multicolumn{7}{|l|}{ Diagnosis } \\
\hline PA/VSD & Reference & & & Reference & & \\
\hline Truncus & $0.31 \pm 0.16$ & $1.36(0.99-1.86)$ & .0563 & $0.38 \pm 0.18$ & $1.46(1.04-2.06)$ & .0311 \\
\hline Ross operation & $-0.17 \pm 0.21$ & $0.84(0.55-1.28)$ & .4273 & $-0.21 \pm 0.24$ & $0.81(0.51-1.28)$ & .3652 \\
\hline Other* & $-0.15 \pm 0.16$ & $0.86(0.63-1.18)$ & .3543 & $-0.14 \pm 0.17$ & $0.87(0.62-1.22)$ & .4182 \\
\hline$z$-score & $-0.02 \pm 0.06$ & $0.98(0.87-1.11)$ & .7771 & $-0.1 \pm 0.07$ & $0.91(0.79-1.03)$ & .1453 \\
\hline
\end{tabular}

$S E$, Standard error; $H R$, hazard ratio; $C I$, confidence interval; $P A / V S D$, pulmonary atresia with ventricular septal defect. *Includes history of nonconduit tetralogy of Fallot repair, transposition of the great arteries with pulmonary stenosis or pulmonary atresia, absent pulmonary valve syndrome, pulmonary atresia with intact ventricular septum, and double-outlet right ventricle.

with nonspecific symptoms for several months before diagnosis. In addition, several patients had normal laboratory studies, and almost $40 \%$ of patients had negative blood cultures. Based on the results of this study, conduit endocarditis should be considered high on the differential diagnosis in patients with a history of a bovine jugular graft RV-PA conduit, even in the setting of negative blood cultures.

This study also demonstrates that up to $30 \%$ of patients with RV-PA conduit endocarditis can be successfully managed medically. This is consistent with the study of Ugaki and colleagues, ${ }^{3}$ in which $38 \%$ of patients with bovine jugular vein conduit endocarditis were treated without surgical replacement.

The recent guidelines published by the American College of Cardiology/American Heart Association consider it "reasonable" to administer prophylaxis for patients with a prosthetic valve. ${ }^{21}$ It is possible that, by following these recommendations, patients might not have received antibiotic prophylaxis before dental procedures, or that antibiotic resistance made the antimicrobial prophylaxis ineffective. Based on our results, we recommend that all patients with bovine jugular grafts receive antibiotic prophylaxis, at least during dental and invasive procedures, to potentially decrease the risk of endocarditis.

In terms of other risk factors for reintervention or replacement, our study confirms previous reports regarding the effects of age, diagnosis, and conduit size. As part of a multi-institutional study involving 241 children undergoing initial RV-PA conduit placement by 17 Congenital Heart Surgeons Society member institutions, Karamlou and colleagues $^{22}$ found that younger age, $z$-score $<-1$, and the presence of pulmonary abnormalities were associated with higher reintervention rates. Several other studies have identified a lower age at implantation as an independent risk factor for reintervention or replacement, regardless of the type of conduit used., ${ }^{2,10-12}$ These findings may be related in part to somatic growth, but possibly also to a higher rate of tissue degeneration in younger patients.

In our series, a diagnosis of truncus arteriosus was a significant predictor for conduit replacement. Other studies have reported a higher incidence of reintervention and replacement in patients with truncus arteriosus. ${ }^{23}$ Some studies have found that placement of an RV-PA conduit in a heterotopic (ie, nonanatomic) position increases the risk of conduit degeneration, with patients undergoing a Ross procedure having a lower incidence of conduit replacement. ${ }^{1,11,12,24}$ This phenomenon may be related to a combination of factors, including increased turbulence at the entrance of the heterotopically placed conduit and possible compression of the conduit owing to its position behind the sternum.

This study has multiple limitations, mainly related to its retrospective nature. Regression models were used with all statistically and clinically significant variables to adjust for the most important covariates and minimize confounding. It is possible, however, that unaccounted-for confounding factors might have biased the results. This study is also the result of a single institutional experience, and as such, results may vary among institutions. At the same time, this also may be one of the study's strengths, 
because of the more uniform conduit selection, management strategy, and follow-up compared with retrospective multi-institutional studies.

In conclusion, despite a lower risk of reintervention seen in bovine jugular grafts, these conduits are associated with a significantly higher risk of late endocarditis. It is clear that there is no perfect RV-PA conduit available. As such, the surgeon and the family must balance the risks of endocarditis with conduit durability. Furthermore, conduit availability and cost (both of which make homografts less favorable) also must be taken into account during the decision making process. At our institution, based on the results of this study, we have decreased the use of bovine jugular grafts in favor of porcine heterografts or homografts. Increased surveillance and suspicion for endocarditis is warranted in patients with a bovine jugular graft conduit.

You can watch a Webcast of this AATS meeting presentation by going to: http://webcast.aats.org/2015/Video/ Wednesday/04-29-15_612_0720_Mery.mp4.

\section{References}

1. Brown JW, Ruzmetov M, Rodefeld MD, Turrentine MW. Right ventricular outflow tract reconstruction in Ross patients: does the homograft fare better? Ann Thorac Surg. 2008;86:1607-12.

2. Dearani JA, Danielson GK, Puga FJ, Schaff HV, Warnes CW, Driscoll DJ, et al. Late follow-up of 1095 patients undergoing operation for complex congenital heart disease utilizing pulmonary ventricle to pulmonary artery conduits. Ann Thorac Surg. 2003;75:399-410.

3. Ugaki S, Rutledge J, Al Aklabi M, Ross DB, Adatia I, Rebeyka IM. An increased incidence of conduit endocarditis in patients receiving bovine jugular vein grafts compared to cryopreserved homograft for right ventricular outflow reconstruction. Ann Thorac Surg. 2015;99:140-6.

4. Malekzadeh-Milani S, Ladouceur M, Iserin L, Bonnet D, Boudjemline Y. Incidence and outcomes of right-sided endocarditis in patients with congenital heart disease after surgical or transcatheter pulmonary valve implantation. J Thorac Cardiovasc Surg. 2014;148:2253-9.

5. Albanesi F, Sekarski N, Lambrou D, Von Segesser LK, Berdajs DA. Incidence and risk factors for Contegra graft infection following right ventricular outflow tract reconstruction: long-term results. Eur J Cardiothorac Surg. 2014;45:1070-4.

6. Boethig D, Westhoff-Bleck M, Hecker H, Ono M, Goerler A, Sarikouch S, et al. Bovine jugular veins in the pulmonary position in adults: 5 years' experience with 64 implantations. Thorac Cardiovasc Surg. 2009;57:196-201.

7. Pettersen MD, Du W, Skeens ME, Humes RA. Regression equations for calculation of z scores of cardiac structures in a large cohort of healthy infants, children, and adolescents: an echocardiographic study. J Am Soc Echocardiogr. 2008;21:922-34.

8. Li JS, Sexton DJ, Mick N, Nettles R, Fowler VG Jr, Ryan T, et al. Proposed modifications to the Duke criteria for the diagnosis of infective endocarditis. Clin Infect Dis. 2000;30:633-8.

9. The Cleveland Clinic Foundation. Parametric analysis of time-related events: procedures. Available at: http://www.lerner.ccf.org/qhs/software/hazard/documents/ overview.pdf. Accessed August 1, 2015.

10. Boethig D, Schreiber C, Hazekamp M, Blanz U, Prêtre R, Asfour B, et al. Risk factors for distal Contegra stenosis: results of a prospective European multicentre study. Thorac Cardiovasc Surg. 2012;60:195-204.

11. Meyns B, Jashari R, Gewillig M, Mertens L, Komárek A, Lesaffre E, et al. Factors influencing the survival of cryopreserved homografts. The second homograft performs as well as the first. Eur J Cardiothorac Surg. 2005;28:211-6.

12. Boethig D, Goerler H, Westhoff-Bleck M, Ono M, Daiber A, Haverich A, et al. Evaluation of 188 consecutive homografts implanted in pulmonary position after 20 years. Eur J Cardiothorac Surg. 2007;32:133-42.

13. Lange R, Weipert J, Homann M, Mendler N, Paek SU, Holper K, et al. Performance of allografts and xenografts for right ventricular outflow tract reconstruction. Ann Thorac Surg. 2001;71(5 Suppl):S365-7.
14. Boethig D, Thies WR, Hecker H, Breymann T. Mid term course after pediatric right ventricular outflow tract reconstruction: a comparison of homografts, porcine xenografts and Contegras. Eur J Cardiothorac Surg. 2005; 27:58-66.

15. Ong K, Boone R, Gao M, Carere R, Webb J, Kiess M, et al. Right ventricle to pulmonary artery conduit reoperations in patients with tetralogy of fallot or pulmonary atresia associated with ventricular septal defect. Am J Cardiol. 2013;111:1638-43.

16. Hickey EJ, McCrindle BW, Blackstone EH, Yeh T Jr, Pigula F, Clarke D, et al Jugular venous valved conduit (Contegra) matches allograft performance in infant truncus arteriosus repair. Eur J Cardiothorac Surg. 2008;33:890-8.

17. Christenson JT, Sierra J, Colina Manzano NE, Jolou J, Beghetti M, Kalangos A Homografts and xenografts for right ventricular outflow tract reconstruction: long-term results. Ann Thorac Surg. 2010;90:1287-93.

18. Shebani SO, McGuirk S, Baghai M, Stickley J, De Giovanni JV, Bu'lock FA et al. Right ventricular outflow tract reconstruction using Contegra valved conduit: natural history and conduit performance under pressure. Eur J Cardiothorac Surg. 2006;29:397-405.

19. Gist KM, Mitchell MB, Jaggers J, Campbell DN, Yu JA, Landeck BF II. Assessment of the relationship between Contegra conduit size and early valvar insufficiency. Ann Thorac Surg. 2012;93:856-61.

20. Urso S, Rega F, Meuris B, Gewillig M, Eyskens B, Daenen W, et al. The Contegra conduit in the right ventricular outflow tract is an independent risk factor for graft replacement. Eur J Cardiothorac Surg. 2011;40:603-9.

21. Nishimura RA, Carabello BA, Faxon DP, Freed MD, Lytle BW, O'Gara PT, et al ACC/AHA 2008 guideline update on valvular heart disease: focused update on infective endocarditis: a report of the American College of Cardiology/American Heart Association Task Force on Practice Guidelines endorsed by the Society of Cardiovascular Anesthesiologists, Society for Cardiovascular Angiography and Interventions, and Society of Thoracic Surgeons. J Am Coll Cardiol. 2008;52: 676-85.

22. Karamlou T, Blackstone EH, Hawkins JA, Jacobs ML, Kanter KR, Brown JW, et al. Can pulmonary conduit dysfunction and failure be reduced in infants and children less than age 2 years at initial implantation? J Thorac Cardiovasc Surg. 2006;132:829-38.

23. Rodefeld MD, Ruzmetov M, Turrentine MW, Brown JW. Reoperative righ ventricular outflow tract conduit reconstruction: risk analyses at follow up J Heart Valve Dis. 2008;17:119-26.

24. Brown JW, Ruzmetov M, Rodefeld MD, Vijay P, Turrentine MW. Righ ventricular outflow tract reconstruction with an allograft conduit in non-Ross patients: risk factors for allograft dysfunction and failure. Ann Thorac Surg. 2005;80:655-63.

Key Words: bovine jugular vein, conduit, Contegra, endocarditis, Hancock, heterograft, homograft, right ventricular outflow tract

\section{Discussion}

Dr S. Emani (Boston, Mass). Thank you, Dr Mery, this is an excellent presentation and a very well done study; particularly I think the statistical analysis is a very important part of this study. You present a very large series of patients who underwent conduit between the pulmonary ventricle and the pulmonary artery. And major findings that I think are different from previous studies include the fact that your bovine jugular vein grafts and porcine heterografts had better freedom from reintervention compared to the pulmonary/aortic homografts; however, the bovine jugular vein graft had a higher incidence of endocarditis.

I have several comments and a couple of questions.

My first comment is, in looking at the Kaplan-Meier freedom-from-reintervention curves, the difference between pulmonary homografts and the bovine jugular 
vein grafts didn't appear to be as impressive as the multivariable analysis seemed to suggest. In fact, the pulmonary homografts appeared to fare better than the aortic homografts, even though your statistical analysis didn't bear that out. And in looking at some of the patient characteristics, the aortic/pulmonary homografts and the bovine jugular vein grafts appeared to be quite similar in terms of their patient type, although different from the porcine heterograft. So I was wondering if you could comment on some of the discrepancy between your multivariable analysis and the hazard curve as depicted by time-based freedom from reintervention, particularly not only the shape of the curve but also the fact that they seemed to all converge really at 10 years, and so is it simply distribution and the failures seem to be much more early in the bovine jugular vein grafts but ultimately the total freedom from intervention was the same at 10 years? So I was wondering if you could comment a little bit on that.

Dr Mery (Houston, TX). Thank you, Dr Emani. The differences between aortic homografts and pulmonary homografts are easily explained by the other variables. We tend to use aortic homografts on patients that we are concerned about pulmonary hypertension, especially patients with truncus arteriosus, and we did find that truncus arteriosus was associated with a significantly higher risk of reintervention. So that may partly explain the difference between aortic homografts and pulmonary homografts on the univariate analysis, which disappears after adjusting for all the other covariates.

Some of the differences between homografts and the other grafts may also be related to other variables that dictate the use of one graft versus the other. When you look at homografts for neonates and infants, the risk of reintervention is significantly higher than that for bovine jugular grafts, and then as patients get older, the results become more similar. Once you account for age, conduit size, and other variables, the differences are not as significant.

Dr Emani. My second question relates to the endocarditis finding, which I think is a significant one and bears some consideration. In the patients who developed endocarditis, was there a preceding episode that could potentially be attributed to this finding, since in your conclusion you mention that prophylactic antibiotics may be one way to prevent this from occurring, or did these patients develop endocarditis without a preceding event?

Dr Mery. Very good question. Unfortunately, it's a retrospective study and we went at length to try to figure out exactly what had happened before. From what we could gather, approximately a third of the patients had a dental or other intervention several months before the onset of endocarditis. However, based on our cardiology notes, all the patients were recommended antibiotic prophylaxis; whether they actually got it or not at the time of intervention we don't know.
What makes it also difficult to relate a particular event to the occurrence of endocarditis is that some patients had symptoms 180 days before diagnosis. It is hard to ascribe a particular event in the setting of such an indolent course. Therefore, I can't say for sure that patients had an inciting event but some of them did have interventions a few months before.

Dr Emani. And I think when you unravel a finding such as this, it has important implications for patients that have already had this graft. We went through this with the Mitroflow valve in the aortic position, we brought back all of our patients and echoed them. Do you think we should do a similar thing for our patients who have the Contegra graft, should we change our surveillance, should we be bringing them back sooner, or how should we handle patients that have had this graft?

Dr Mery. We do think increased surveillance is warranted for these patients. Now, how does that look like? I'm not entirely sure. But at least, these patients should be followed more closely. And most importantly, if a patient has malaise or low-grade fever, there should be a higher index of suspicion for endocarditis. Looking back at some of these patients, they had seen several physicians before and the diagnosis had been missed.

We have reached out to the company to let them know because I think it is an important finding that has to be taken into account. These findings are in line with some smaller series from Switzerland, Germany, Canada, and Paris that have also shown a concerning high incidence of late endocarditis on patients with Contegra grafts.

Dr Emani. My final question is, if you have a neonate with truncus arteriosus, what is your current conduit of choice?

Dr Mery. That is the real question. Unfortunately, there is no optimal conduit. If you look at the reintervention rates, the reintervention rates for homografts are higher. That being said, because of this risk of endocarditis, we have recently swayed away from Contegra grafts. We would likely use a homograft, either an aortic homograft or a pulmonary homograft.

Dr Emani. How about for an adolescent or young adult?

Dr Mery. We have moved more into using Hancock porcine heterografts, based on the results of this study. We used to use a mix of Contegras and Hancocks. Now, after this study, we're more likely to use Hancocks or in some cases homografts.

Dr J. Brown (Indianapolis, Ind). I very much enjoyed your paper. I think endocarditis is a surrogate for turbulence, and I think that's why patients maybe with truncus had a higher incidence of endocarditis. We have a similar population of patients since back to 1999. Our incidence of endocarditis is about half of what yours is. But I think we routinely advocate using antibiotic prophylaxis for any dental or other thing, so that may make a difference. 
If there were a better conduit out there and an easier-touse conduit, we might go back to it. But we don't want to go back to the aortic/pulmonary homograft problems because those valves in those conduits don't work as well as the valve in the Contegra, so we're going to continue to do it until something else better comes along.

Dr Mery. Unfortunately, there is no optimal conduit for $\mathrm{RV}$-to-PA reconstruction.

Readers who found these articles interesting may also like to read the following papers found in recent and future issues of our sister publications, Seminars in Thoracic and Cardiovascular Surgery and Operative Techniques in Thoracic and Cardiovascular Surgery!

\section{Congenital}

State of the Art: Interrupted Aortic Arch. Richard Jonas. Semin Thorac Cardiovasc Surg 2015; Summer; 27(2):177-188.

Original Submission: Should Tricuspid annuloplasty be performed with pulmonary valve replacement for pulmonary regurgitation in repaired tetralogy of fallot? Pranava Sinha. Semin Thorac Cardiovasc Surg 2015; Summer; 27(2): 159-165.

Editorial Commentary: PI Leads to RVE, Which Leads to TR, Which Leads to More RVE, Which Leads to More TR: A Vicious Cycle? Charles B. Huddleston. Semin Thorac Cardiovasc Surg 2015; Summer; 27(2): 166-167.

Original Submission: Unsatisfactory early and late outcomes after Fontan surgery delayed to adolescence and adulthood. Yves D’Udekem. Semin Thorac Cardiovasc Surg 2015; Summer; 27(2):168-174.

Editorial Commentary: The Fontan Operation: Is Timing Everything? Harold M Burkhart. Semin Thorac Cardiovasc Surg 2015; Summer; 27(2): 175.

Discussions in Cardiothoracic Treatment and Care: Tetralogy of Fallot. Charles Fraser. Semin Thorac Cardiovasc Surg 2015; Summer; 27(2):189-204.

Current Readings: Pulmonary Valve Replacement for Pulmonary Valve Insufficiency in Formerly Repaired Tetralogy of Fallot. Brian Kogon. Semin Thorac Cardiovasc Surg 2015; Spring; 27(1):57-64.

Original Submission: Preliminary experience in the use of an extracellular matrix (CorMatrix) as a tube graft: Word of caution. Narutoshi Hibino. Expected Publication December 2015.

Original Submission: Relationship of normal aortic valve cusp dimensions: a tool to optimize cusp reconstruction valvuloplasty. Sujata Subramanian. Expected Publication December 2015.

Original Submission: Outcomes of truncus arteriosus repair in children: 35 years of experience from a single institution. Igor Konstantinov. Expected Publication December 2015.

Original Submission: Efficacy of artificial chordal reconstruction for idiopathic severe mittral regurgitation due to chordal rupture in infancy. Sadahiro Sai. Expected Publication December 2015.

Original Submission: The mid-term outcomes of bioprosthetic pulmonary valve replacement in children. Takeshi Shinkawa. Expected Publication December 2015.

Original Submission: Health-related quality of life in adult survivors after the Fontan operation. James Kirklin. Expected Publication December 2015.

Repair of Atrioventricular Septal Defects: The 2-Patch Sandwich Technique. Hagi Dekel. Oper Tech Thorac Cardiovasc Surg 2015; Spring; 20(1):63-74.

Classic Single-Patch Repair of Atrioventricular Septal Defects. Anees J. Razzouk. Oper Tech Thorac Cardiovasc Surg 2015; Spring; 20(1):75-86.

Melody Valve for Mitral Valve Replacement. Sitaram M. Emani. Oper Tech Thorac Cardiovasc Surg 2014; Winter; 19(4):454-463. Single-Stage Neonatal Repair of Taussig-Bing Anomaly. Bahaaldin Alsoufi. Oper Tech Thorac Cardiovasc 2014; Winter; 19(4): 464-481

Repair of Anomalous Coronary Artery from the Pulmonary Artery by Aortic Implantation. Anthony Azakie. Expected Publication December 2015. 

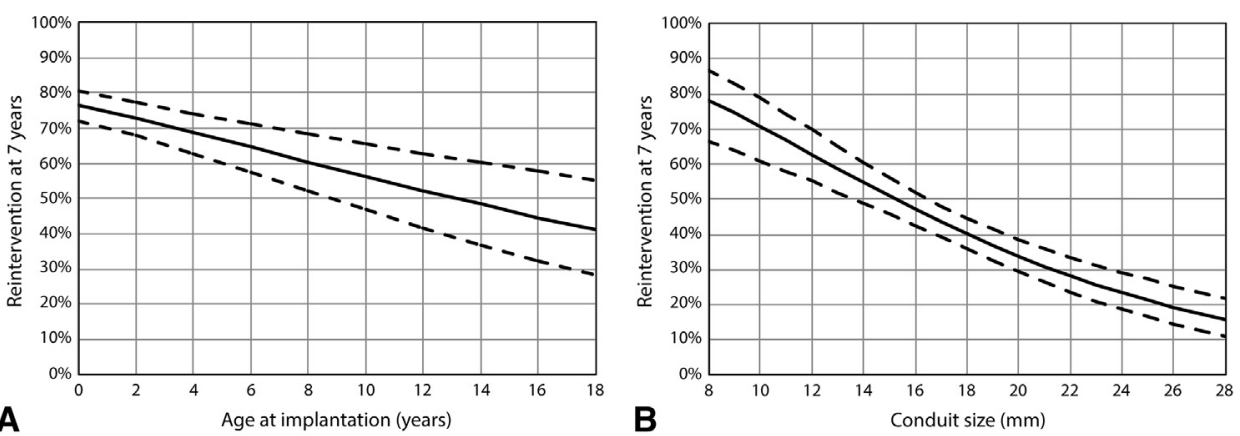

FIGURE E1. Risk-adjusted nomograms showing the relationship between patient age (A) and conduit size (B) with the likelihood of first reintervention by 7 years after conduit implantation. Solid lines are parametric point estimates. Dashed lines represent confidence limits equivalent to 1 standard error (68\%). 

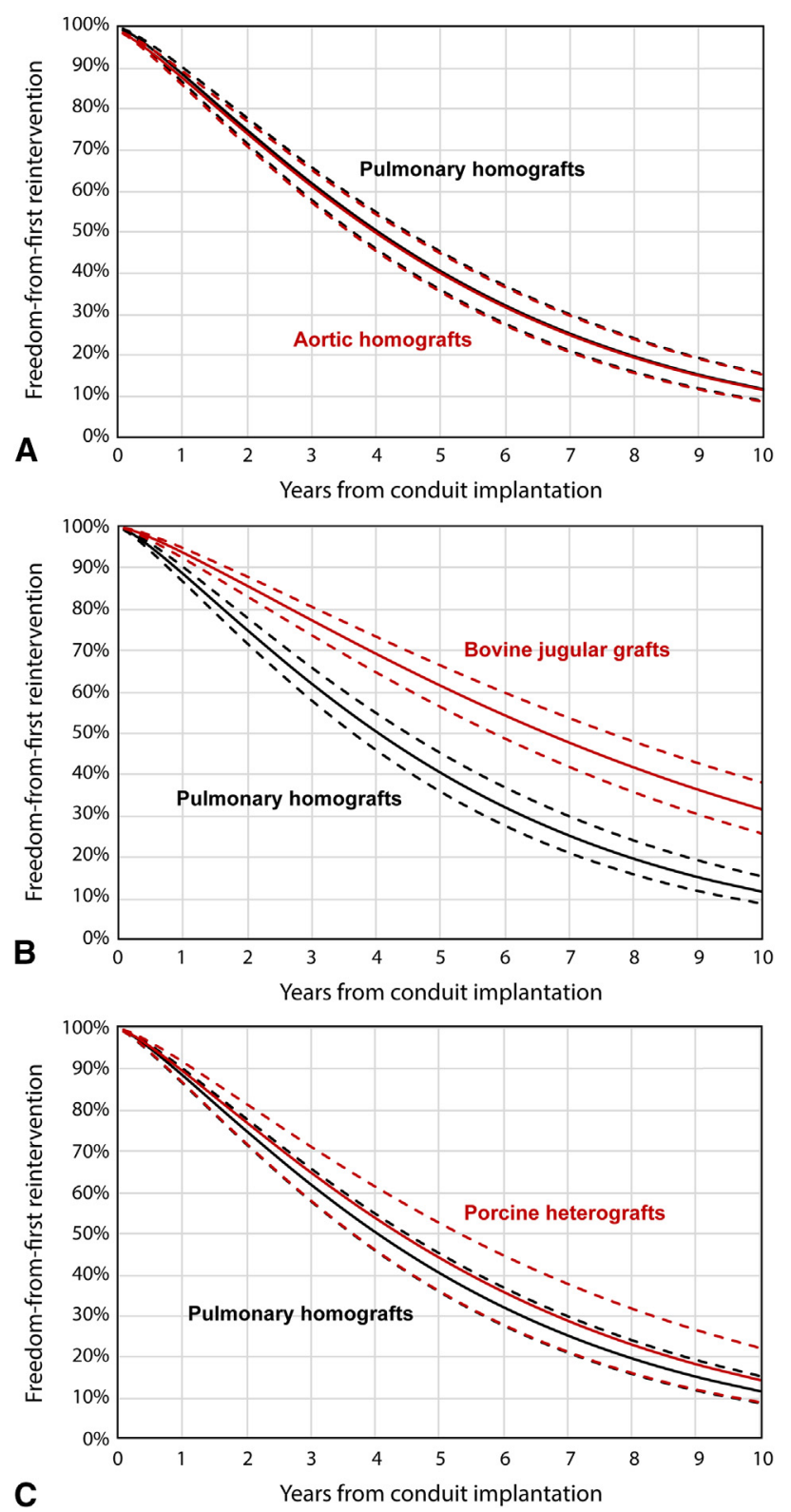

FIGURE E2. Risk-adjusted estimates for freedom from first reintervention by conduit type. Solid lines are parametric point estimates. Dashed lines represent confidence limits equivalent to 1 standard error (68\%). (A) Pulmonary (black) and aortic (black) homografts. (B) Bovine jugular grafts (red) and pulmonary homografts (black). (C) Porcine heterografts (red) and pulmonary homografts (black).
TABLE E1. Conduit characteristics at the time of first reintervention by conduit type

\begin{tabular}{|c|c|c|c|c|c|}
\hline $\begin{array}{c}\text { Variable, } \\
\text { n (\%) }\end{array}$ & $\begin{array}{c}\text { Overall } \\
(n=290)\end{array}$ & $\begin{array}{c}\text { Homograft } \\
(\mathrm{n}=186)\end{array}$ & $\begin{array}{c}\text { Bovine } \\
\text { jugular } \\
\text { graft } \\
(\mathrm{n}=67)\end{array}$ & $\begin{array}{c}\text { Porcine } \\
\text { heterograft } \\
(\mathbf{n}=\mathbf{3 7})\end{array}$ & $\begin{array}{c}P \\
\text { value }\end{array}$ \\
\hline Insufficiency & $178(61)$ & $130(70)$ & $40(60)$ & $8(22)$ & $<.0001$ \\
\hline Stenosis & $214(74)$ & $141(76)$ & $44(66)$ & $29(78)$ & .21 \\
\hline Proximal & $92(32)$ & $62(33)$ & $12(18)$ & $18(49)$ & $<.0001$ \\
\hline Distal & $45(16)$ & $24(13)$ & $19(28)$ & $2(5)$ & .002 \\
\hline Within & 77 (27) & $55(30)$ & $13(19)$ & $9(24)$ & .26 \\
\hline Pseudoaneurysm & $20(7)$ & $13(7)$ & $5(7)$ & $2(5)$ & .92 \\
\hline
\end{tabular}

